\title{
ELEGTRICAL RESISTIVITY MEASUREMENTS ON ICE SHEETS
}

\author{
By M. Hochstein
}

(Geophysical and Polar Research Center, University of Wisconsin, Madison, Wisconsin, U.S.A.)*

\begin{abstract}
The electrical resistivity of firn and ice of ice sheets is a function of the "base" resistivity, the contact resistance between the grains, and the temperature. At greater depths temperature is the predominant influence, and observed resistivity curves can be explained by temperature variations which agree partly with the theories of heat conduction in ice sheets.
\end{abstract}

RÉsumé. Mesures des résistivités électriques des calottes de glace. La résistivité du névé et de la glace des calottes glaciaires est fonction de la résistivité de "base", de la résistance de contact des grains et de la température. Pour de grandes profondeurs, la température est l'élément déterminant; les courbes de résistivité obtenues peuvent être expliquées par des variations de température qui sont en partie en accord avec les théories de la conduction thermique dans les calottes glaciaires.

Zusammenfassung. Elektrische Widerstandsmessungen auf Inlandeis. Der spezifische Widerstand von Eis und Firn des Inlandeises ist abhängig von der "Grundleitfähigkeit", dem Kontaktwiderstand im Kornverband und der Temperatur. In grösseren Tiefen überwiegt der Temperatureinfluss; die Widerstandskurven können durch Temperaturänderungen erklärt werden, die mit den Theorien der Wärmeleitung im Inlandeis teilweise übereinstimmen.

\section{INTRODUCTION}

During the Expédition Glaciologique Internationale au Groenland (E.G.I.G.) in I 959 and the U.S. Antarctic Research Programs in $\mathrm{I}_{96} \mathrm{I}-62$ and $\mathrm{I}_{962}-63$, several D.C. electrical resistivity measurements were made on the Greenland Ice Sheet and in Antarctica on the small ice cap of Roosevelt Island and on the Ross Ice Shelf. These measurements were made in order to study the variation of the specific resistivity with depth and to investigate the existence of low resistivity layers at the bottom of the ice sheet.

\section{METHOD}

The Schlumberger electrode configuration was used throughout the investigations. In making the measurements, the current $I$ was limited to $\mathrm{I}-2 \mathrm{~mA}$. by the available voltage sources and a combined contact resistance of about $\mathrm{I}-2 \mathrm{M} \Omega$. at the current electrodes. Because of these limitations and low resistivities at depth, the electrode spacing $L / 2$ could only be increased to about $\mathrm{I} \cdot 5 \mathrm{~km}$. before the potential drop $\Delta V$ could no longer be measured accurately above the background of extraneous potential changes at the potential electrodes.

Standard graphs and auxiliary diagrams given by CGG (1955) and Buchheim (1958) were used for interpretation of the data. One graph was computed according to a theorem of Flathe (1955).

\section{BAGKGROUND}

By I $96_{1}$ it was known that there must exist two different ranges of resistivity for glacier ice:

$$
\begin{gathered}
\rho>10 \mathrm{M} \Omega \text {.m. at about } 0^{\circ} \mathrm{C} \text {., i.e. on temperate glaciers, and } \\
\rho \simeq 0 . \mathrm{I} \mathrm{M} \Omega \text {.m. at }-\mathrm{I} 0^{\circ} \mathrm{C} \text {. on cold glaciers and ice sheets. }
\end{gathered}
$$

Locally resistivities between $\mathrm{I}$ and $2 \mathrm{M} \Omega . \mathrm{m}$. can be found on cold glaciers and thin ice shelves, as reported by Meyer and Röthlisberger (1962) and by Vögtli (Apollonio and others, I96r).

\footnotetext{
* Present address: Geophysics Division, Department of Scientific and Industrial Research, Wellington, New Zealand.
} 
Cold ice with similarly high resistivity was found on the Ross Ice Shelf near McMurdo Sound (Antarctica) by Robertson and Macdonald (1962). In the same area in 1961 , the author measured a resistivity of $\mathrm{I} \cdot 7 \mathrm{M} \Omega . \mathrm{m}$. in ice warmer than $-20^{\circ} \mathrm{C}$.

On the cold névé of continental ice sheets resistivity is a function of depth. The 1959 measurements on the Greenland Ice Sheet (Hochstein, 1965) showed that the resistivity decreased sharply, reaching an unexpectedly low value of less than $0 \cdot \mathrm{I} \mathrm{M} \Omega$.m. at an electrode spacing of $L / 2=600 \mathrm{~m}$. At greater spacings, $\rho_{\mathrm{a}}$ remained nearly constant (Fig. I). If the

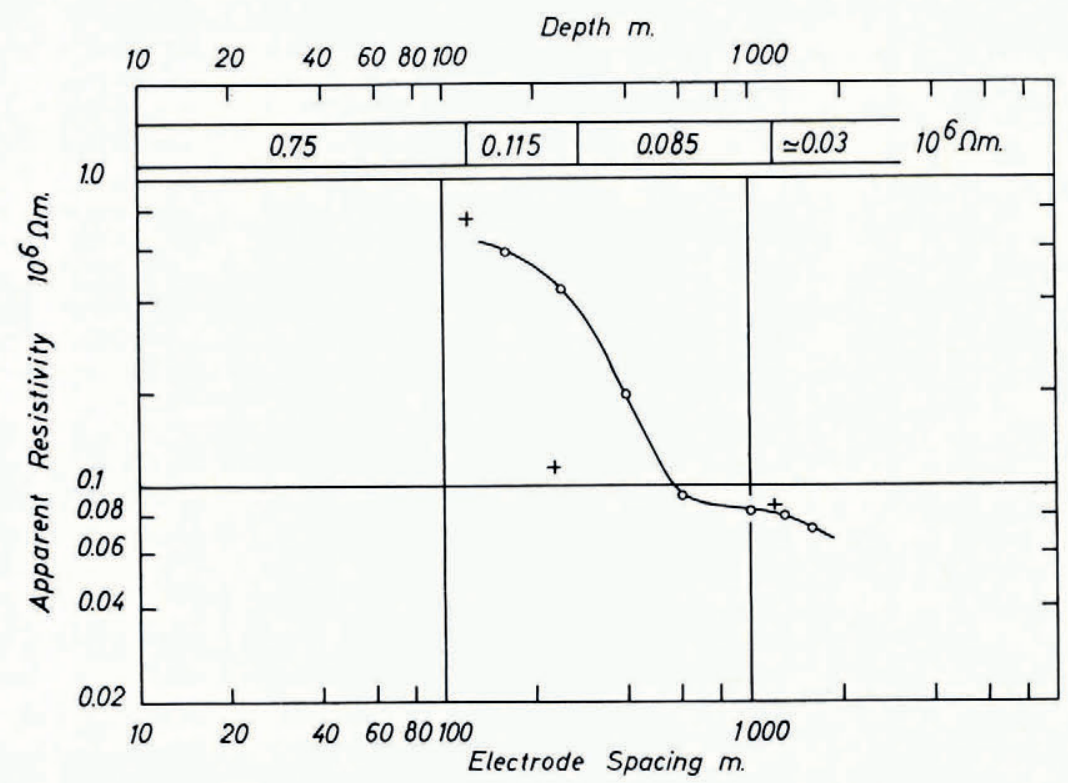

Fig. I. Apparent resistivity curve at "Station Centrale" (calculated resistivity-depth column is shown in the upper part of the figure; crosses indicate the origin of the applied model curves)

decrease of resistivity is an effect of densification, it should also be found in cores. Kopp ( 1962 ) investigated the resistivity of some cores taken by the glaciological party of E.G.I.G. near "Station Dumont" (Greenland), but found no relation between the density $\gamma$ and the resistivity $\rho$. Furthermore, the resistivities of the cores were Io-10o times greater than values obtained from field measurements. Samples of fresh compressed snow, however, showed a linear variation of $\log \left(\rho_{\mathrm{i}} / \rho\right)$ with $\gamma$ where $\rho_{\mathrm{i}}$ is the initial resistivity. Kopp also showed that the resistivity of firn cores and compressed snow samples was affected by the temperature, following the same law as the resistivity of pure ice:

$$
\rho=\rho_{\mathrm{c}} \exp (\epsilon / k T)
$$

where $\rho_{\mathrm{c}}$ is a constant, $T$ the absolute temperature, $\epsilon$ the activation energy, and $k$ Boltzmann's constant $\left(8.62 \times \mathrm{IO}^{-5} \mathrm{eV} .{ }^{\circ} \mathrm{C}\right.$. $=\mathrm{I} \cdot 9^{8} \mathrm{cal} . / \mathrm{mole}{ }^{\circ} \mathrm{C}$. $)$. In all cases the activation energy for snow and firn was greater than the activation energy of pure ice.

In $1961-62$, resistivity measurements with short spreads were made on the top and at the border of the Roosevelt Island ice cap in order to determine if horizontal strain could affect resistivity. The temperature at a depth of $10 \mathrm{~m}$. was about the same in both locations. No measurable effect could be observed. In $1962-63$ resistivity measurements on Roosevelt Island were made with long profiles (electrode distances up to $L / 2=\mathrm{I} \cdot 6 \mathrm{~km}$.) on the top of the island and on the ice shelf near the margin of the island. The apparent resistivity curves 
(Figs. 2 and 3 ) show the expected decrease at shorter spreads. On the ice cap the apparent resistivity reached a minimum at $L / 2=1,000 \mathrm{~m}$. with $\rho_{\mathrm{a}}=0.12 \mathrm{M} \Omega . \mathrm{m}$. and then increased, whereas on the ice shelf the resistivity decreased continuously. During the same season, the influence of densification upon resistivity was studied by measuring the resistivity in cores from a $15 \mathrm{~m}$. drill hole.

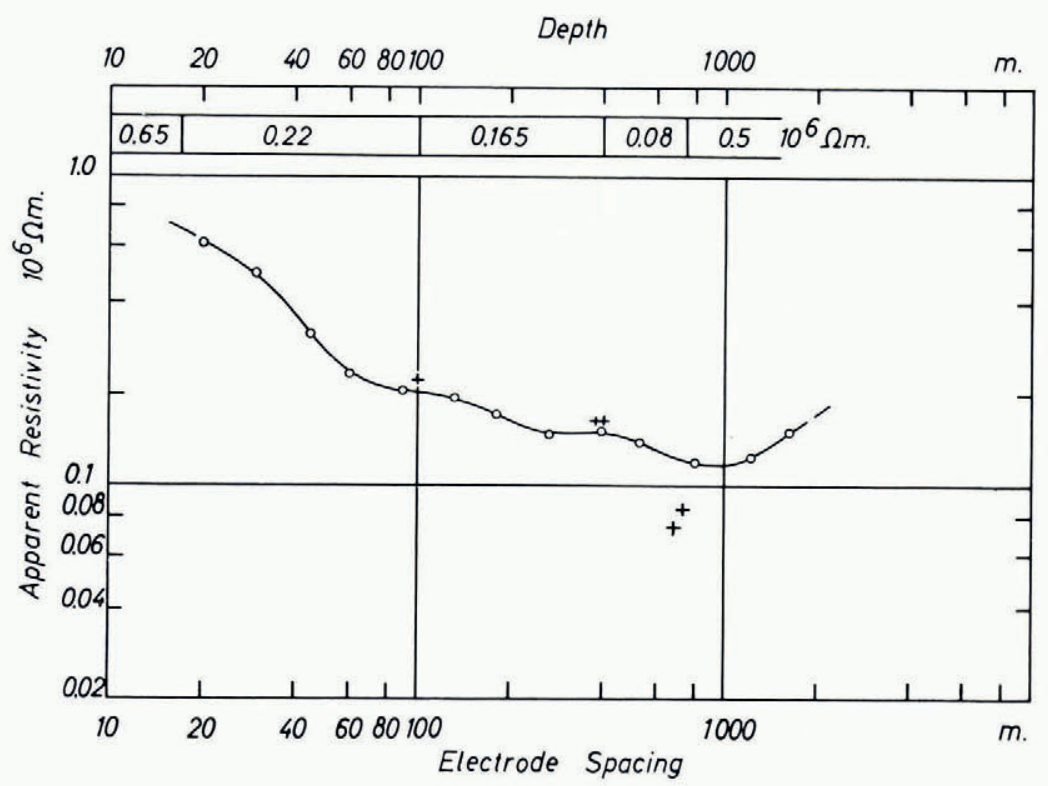

Fig. 2. Apparent resistivity curve at "Camp Wisconsin" on Roosevelt Island

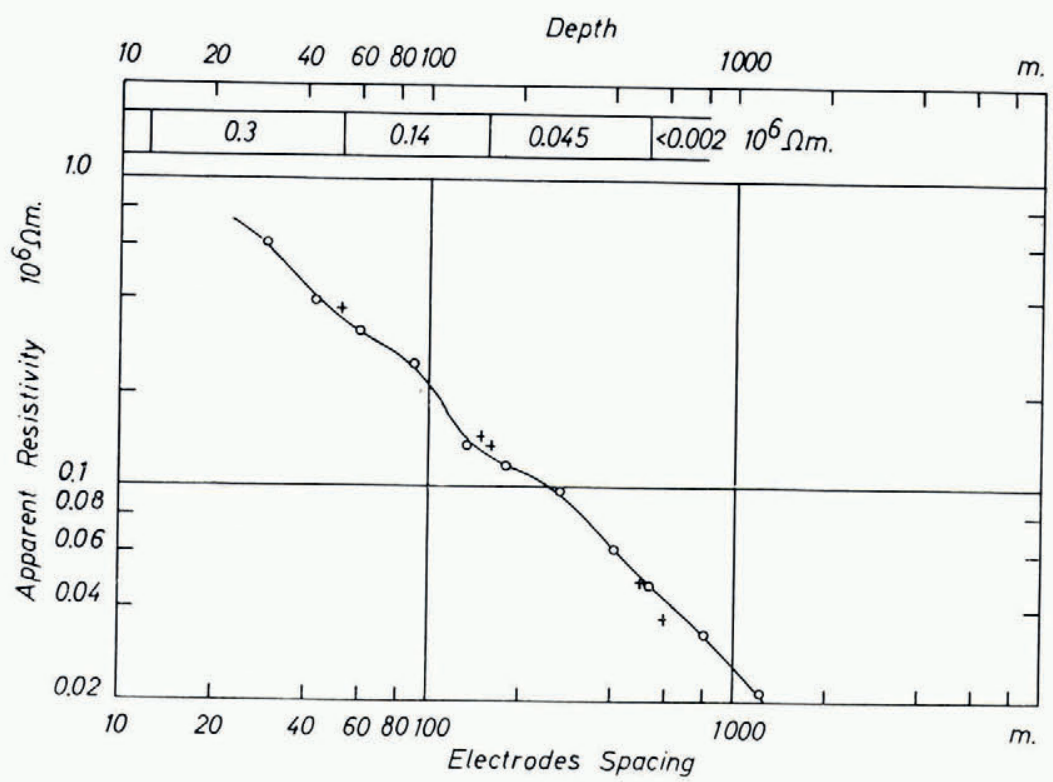

Fig. 3. Apparent resistivity curve on the Ross Ice Shelf near Roosevelt Island 


\section{The Resistivity of Firn and Ice on Ice Sheets}

From earlier measurements, we can draw the conclusion that the resistivity of sedimentary ice is a function of (I) the "base" resistivity, (2) the contact resistance between the grains, (3) the temperature. Other factors, such as the past history of the ice, may also be important but will not be discussed for lack of information.

(I) According to recent theories (Jaccard, 1959; Gränicher, I958) the conductivity of pure ice results from the presence of $\mathrm{OH}^{-}$and $\mathrm{H}_{3} \mathrm{O}^{+}$ions together with lattice defects.

In order to explain the difference in resistivity between cold and temperate glacier ice it was first thought that the resistivity of sedimentary ice is generally lowered by chemical impurities (i.e. electrolytic conductivity) and that a different distribution of these impurities may cause the difference in resistivity. But in the case of electrolytic conductivity the activation energy $\epsilon$ of sedimentary ice should be smaller than measured; besides, near the freezing point of the "ice-electrolyte" a jump of resistivity should occur which was not observed (Hochstein, I965).

If the conductivity of sedimentary ice results from chemical and lattice defects a different production of these defects can be responsible for the observed various resistivities. Recrystallization - which is the main difference between cold and temperate glacier ice - could affect the equilibrium of the defects. Laboratory measurements by Kopp (1962) indeed show an increase of the resistivity of compressed snow during recrystallization. Field measurements on the other hand give evidence of a layer with high resistivity at the bottom of cold glaciers in North Greenland and at the bottom of the ice sheet near the coast in mid Greenland (Meyer and Röthlisberger, I962; Hochstein, I965) and since recrystallization should only occur at the bottom of ice sheets the field results also support the conclusion that apparently the difference of resistivity between cold and temperate glacier ice is related to the rate of recrystallization.

(2) In firn and ice, resistivity also depends upon the contact resistance between the grains which is a function of grain size and pressure. With increasing grain size and increasing pressure the contact area between grains must become larger, the contact resistance consequently must decrease.

The resistivity measurements in Greenland during E.G.I.G. suggested that densification has an influence upon resistivity. Laboratory measurements made by Kopp ( 1962 ) gave proof for compressed snow samples; between the available density range $0.2 \mathrm{~g} . / \mathrm{cm} .{ }^{3}<\gamma<0.6$ g. $/ \mathrm{cm} .^{3}$ the variation of resistivity could be described by:

$$
\rho=a \exp (b \gamma) \quad T=\text { const. }
$$

The coefficient in the exponent was affected by the grain size. Kopp got the values $-12 \cdot 3$ for fresh snow, $-9 \cdot \mathrm{I}$ for powder snow, and -3.9 for granulated snow (transforming his graphs of $\log \left(\rho_{\mathrm{i}} / \rho\right)$ versus $\gamma$ into $\left.\rho=a \exp (b \gamma)\right)$. But resistivities of firn cores from Greenland scattered over a broad range and did not show a relationship between resistivity and density.

In order to check the influence of densification we measured resistivity and density of core samples directly in the field during the $1962 / 63$ season at "Camp Wisconsin" on Roosevelt Island (lat. $79^{\circ} 1^{\prime}$ S.; long. $162^{\circ}{ }^{\prime} 5^{\prime}$ W., elevation $560 \mathrm{~m}$., accumulation $\simeq 16 \mathrm{~g} . / \mathrm{cm} .^{2} \mathrm{yr}$., Io-metre temperature $-23.0^{\circ} \mathrm{C}$.). Since the work was done in a $3 \mathrm{~m}$. pit the temperature $t$ of the cores did not change more than $\mathrm{I}$ or $2{ }^{\circ} \mathrm{C}$. from $-22^{\circ} \mathrm{C}$. during the measurements $(t$ will be used throughout for Centigrade temperatures). Resistivity and density were measured immediately after drilling. The cores were stored in the pit and some remeasured after one and a half months, but no significant difference could be found. Brass plates frozen to the ends of the cores were used as electrodes. The resistance $R$ was measured with a Keithley electrometer (model 6ro A) and the resistivity calculated from: $\rho=R q \mid l$, where $q$ is the crosssectional area and $l$ the length of the core. The experimental error of these measurements was about IO-25 per cent due to uncertainty about contact resistance (about $2 \mathrm{M} \Omega$.), anisotropy, and polarity. The field strength in the cores did not exceed $2 \mathrm{~V} . / \mathrm{cm}$. We found that the 
average resistivity (over I m. length) decreased from I $\cdot 05 \mathrm{M} \Omega . \mathrm{m} .\left(\gamma=0.426 \mathrm{~g} . / \mathrm{cm} .{ }^{3}\right)$ at $2.5 \mathrm{~m}$. depth to $0.3^{8} \mathrm{M} \Omega . \mathrm{m}$. $\left(\gamma=0.593 \mathrm{~g} . / \mathrm{cm} .^{3}\right)$ at $14.5 \mathrm{~m}$. depth. Plotting $\log \rho$ against $\gamma$ (Fig. 4a), we see that between $\gamma=0.35 \mathrm{~g} . / \mathrm{cm} .{ }^{3}$ and $\gamma=0.60 \mathrm{~g} . / \mathrm{cm} .{ }^{3}$ the resistivity approximately follows the equation:

$$
\rho=\mathrm{r} 0 \cdot 8 \exp (-5 \cdot 8 \gamma) \mathrm{M} \Omega . \mathrm{m} . \quad t \simeq-22^{\circ} \mathrm{C} .
$$

Assuming that the density on the island is constant $\left(\gamma=0.9 \mathrm{~g} . / \mathrm{cm} .^{3}\right)$ at a depth greater than I $00 \mathrm{~m}$. (the temperature at this depth is still about $-22^{\circ} \mathrm{C}$. anticipating results shown at the end of the paper) from Equation (2a) we get a resistivity of $\rho=0 \cdot 08_{5} \mathrm{M} \Omega . \mathrm{m}$. The interpretation of the resistivity curve (Fig. 2) shows, however, that the resistivity around roo m. depth is still about o. I9 M $\Omega$.m. Equation (2) seems, therefore, only applicable to a limited range of density and thus $\gamma$ is not an appropriate parameter to describe the variation of resistivity with depth.*

As the next step we tried to correlate resistivity and hydrostatic pressure. Assuming that the contact resistance of the grains inside the cores will not change if the pressure is removed by drilling, we can plot $\log \rho$ versus $\log p$ at the depth $z$ where the pressure $p=\int_{0}^{z} \gamma_{z} d z$ (Fig. 4 b). In this plot the points indicate a linear relation, i.e. explicitly a function of the type:

$$
\rho=\rho_{\mathrm{c}}{ }^{\prime} p^{x}
$$

where $\rho_{\mathrm{c}}$ ' and $x$ are constants. In addition to the directly measured resistivities the interpretation of the resistivity curve at "Camp Wisconsin" (Fig. 2) yields average resistivities for the second and third layers of $\rho_{2}=0.22 \mathrm{M} \Omega . \mathrm{m}$. and $\rho_{3}=0 . \mathrm{I}_{5} \mathrm{M} \Omega . \mathrm{m}$. at average depths of

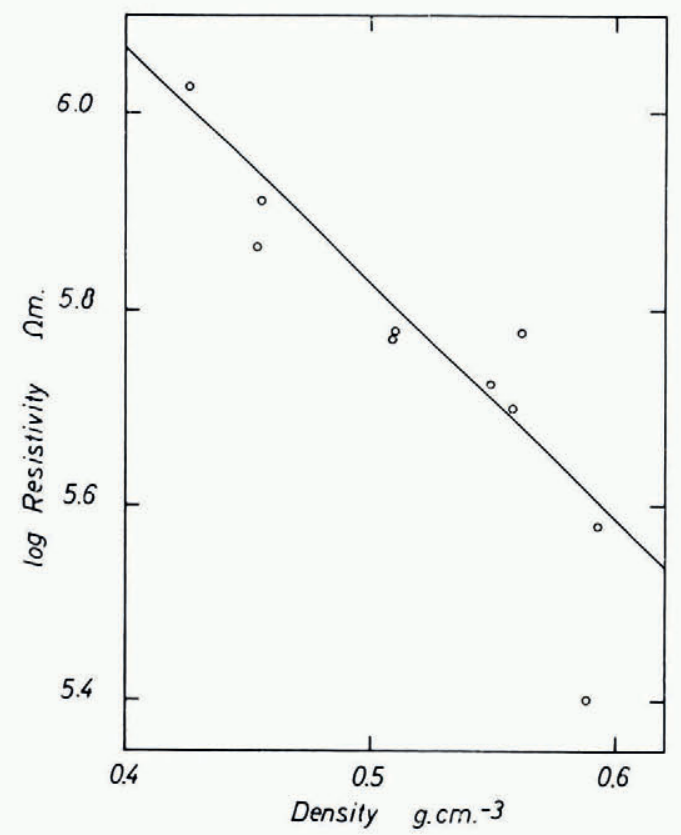

Fig. 4a. Variation of resistivity with density on Roosevelt Island

\footnotetext{
* In an earlier version of the paper a change of exponent in equation (2a) at high densities was assumed. Röthlisberger (personal communication) believes that this assumption was well justified, because it is known that the transition from snow to ice, i.e. the change from communicating pores to closed ones, occurs at densities between 0.82 and $0.83 \mathrm{~g} . / \mathrm{cm} .{ }^{3}$, and a change of electrical behaviour at the transition is possible.
} 
$z_{2}=58.5 \mathrm{~m}$. and $z_{3}=250 \mathrm{~m}$. The temperature at these depths $\left(-23^{\circ} \mathrm{C} .<t<-2 \mathrm{I}^{\circ} \mathrm{C}\right.$. $)$ is about the same as the temperature of the cores. Therefore we can plot these values also in Figure $4 \mathrm{~b}$ where they match the linear function fairly well. A least-squares fit of the constants gives the equation:

$$
\rho=0 \cdot 4^{\mathrm{I} 2} p^{-0.35} \mathrm{M} \Omega \cdot \mathrm{m} . \quad t \simeq-22^{\circ} \mathrm{C} .
$$

where $p$ is the hydrostatic pressure in $\mathrm{kg} . / \mathrm{cm}^{2}$. According to ( $3 \mathrm{a}$ ) the variation of resistivity due to increasing pressure is small at greater depths. At "Camp Wisconsin" for example the resistivity is lowered about 20 per cent between $250 \mathrm{~m}$. and $500 \mathrm{~m}$. and about $\mathrm{I} 4$ per cent between $500 \mathrm{~m}$. and $750 \mathrm{~m}$.

(3) The resistivity of pure and sedimentary ice is affected by the temperature, following the law of Arrhenius given in equation (I). The activation energy $\epsilon$ of pure ice according to Jaccard (1959) is about $0.6 \mathrm{I} \mathrm{eV}$. Kopp ( 1962 ) found values of $\epsilon=0.7$ to $0.8 \mathrm{eV}$. in snow samples and $\epsilon=0.9$ to $\mathrm{I} \cdot \mathrm{I} \mathrm{eV}$. in firn samples.

For a detailed interpretation of resistivity curves on ice sheets, the exact value of the activation energy is important. Comparison of parallel resistivity curves provides a first check on $\epsilon$.

In Greenland the resistivity curves of "Station Centrale" and "Point Nord" are nearly parallel up to $L / 2=400 \mathrm{~m}$., the ratio of the apparent resistivities is about $\mathrm{I} \cdot 5: \mathrm{I}$ to $2: \mathrm{I}$ and the temperature about $-28^{\circ} \mathrm{C}$. at "Station Centrale" and $-2 \mathrm{I}^{\circ} \mathrm{C}$. at "Point Nord". These temperatures are constant at least up to a depth of $300 \mathrm{~m}$. Assuming the same structure and density gradient, we get from equation ( $\mathrm{I}$ ) a value of 0.3 to $0.55 \mathrm{eV}$. for the activation energy (Hochstein, 1965).

The resistivity curves from Roosevelt Island and the Ross Ice Shelf (Figs. 2 and 3 ) are also nearly parallel up to $L / 2=60 \mathrm{~m}$. The $10 \mathrm{~m}$. temperatures at these two locations are $-23^{\circ} \mathrm{C}$. and $-26^{\circ} \mathrm{C}$., the ratio of the apparent resistivities is about $0.8:$ I which yield for $\epsilon$ a value of $0.35 \mathrm{eV}$.

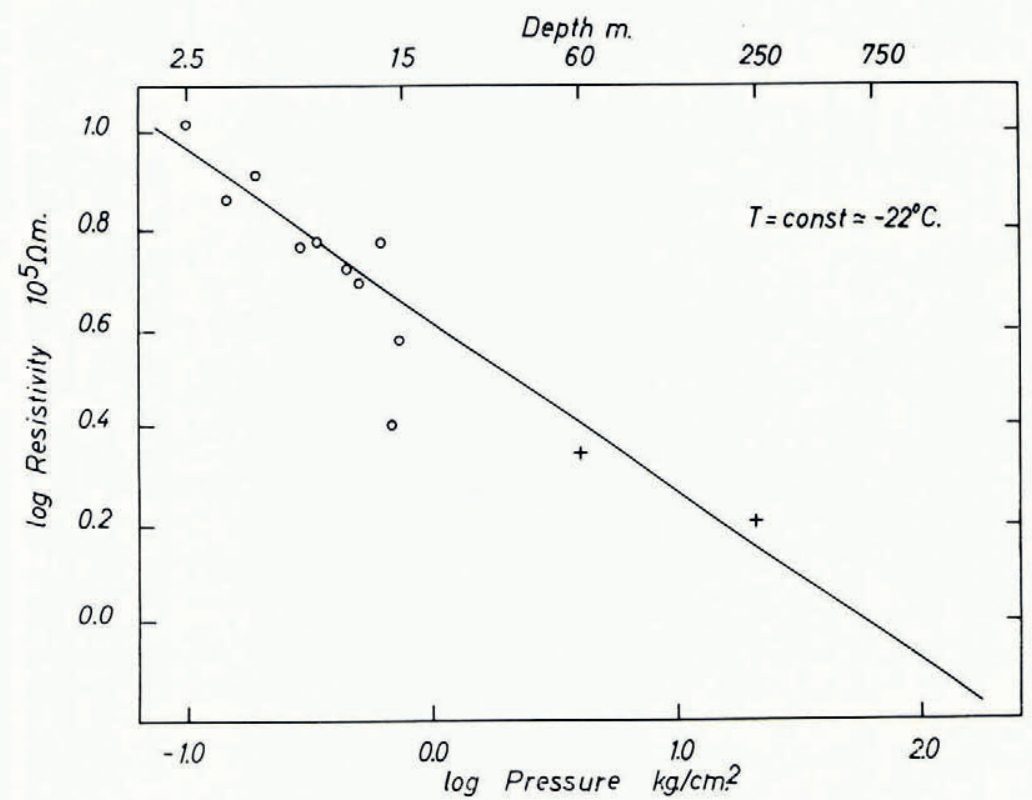

Fig. 4 b. Variation of resistivity with hydrostatic pressure on Roosevelt Island. Measured (averaged) resistivities on core samples are marked with circles, crosses indicate calculated resistivities from the apparent resistivity curve 
An average value of $\epsilon$ at greater depths can be derived from a single resistivity curve if, at two different depths $z_{\mathrm{I}}$ and $z_{2}$, the corresponding resistivities $\rho_{\mathrm{I}}$ and $\rho_{2}$ and temperatures $t_{1}$ and $t_{2}$ are known.

On the ice shelf near Roosevelt Island interpretation of the apparent resistivity curve (Fig. 3) gave the following values: at ro m. depth $\rho_{1}$ was about $0.65 \mathrm{M} \Omega . \mathrm{m}$., while at the bottom of the floating ice shelf at $500 \mathrm{~m}$. depth $\rho_{2}$ was about 0.02 to $0.035 \mathrm{M} \Omega . \mathrm{m}$. The temperature at these depths were about $T_{\mathrm{I}}=26^{\circ} \mathrm{C}$. and $\mathrm{T}_{2}=-2^{\circ} \mathrm{C}$. If we consider the influence of hydrostatic pressure according to equation ( $3 \mathrm{a}$ ) the resistivity $\rho_{\mathrm{I}}$ would be lowered to about $0 \cdot \mathrm{I} 35 \mathrm{M} \Omega . \mathrm{m}$. at $500 \mathrm{~m}$. depth. From equation (I) the corresponding activation energy is $0.3^{8} \pm 0 \cdot \mathrm{I} \mathrm{eV}$. This figure agrees with the value of $\epsilon=0.3$ to $0.55 \mathrm{eV}$. derived from parallel curves.*

The variation of resistivity with temperature is nearly the same in Greenland and Antarctica. The activation energy of cold sedimentary ice of ice sheets is about $0.4 \mathrm{eV}$. and apparently does not change with depth. In both cases, the field results give a lower value for $\epsilon$ than the laboratory measurements of snow and firn samples which could have been disturbed by recrystallization.

As long as the exact influence of the structure and composition (impurity content) of firn and ice upon the resistivity is unknown, we cannot compare and interpret the absolute resistivity of firn and ice of ice sheets. For example, the ratio of the resistivities at greater depths at "Station Centrale" and Roosevelt Island, after correction for pressure and temperature, is still about $2: \mathrm{I}$. In the special case of two adjacent locations with nearly the same snow structure, accumulation, and crystal orientation, it should be possible to interpret variations of the resistivity curve (insofar as they are not due to the influence of the substratum) in terms of pressure and temperature variations alone. In this way we could interpret the resistivity curves from "Camp Wisconsin" and Ross Ice Shelf (Figs. 2 and 3), as these locations are only about $50 \mathrm{~km}$. apart. Reasonable results were also obtained in Greenland at "Station Centrale" and "Point Nord", which are about $300 \mathrm{~km}$. apart. In this paper only a short review of the interpretation of "Station Centrale" is given; for detailed information see Hochstein (ig65).

\section{Discussion of Measurements in Antarctica and Greenland}

The interpretation of observed resistivity curves was undertaken by approximating the continuously decreasing resistivity by a multi-layered model, i.e. a step function.

The apparent resistivity curves, determined from measurements at the centre of Roosevelt Island (Fig. 2) (lat. $79^{\circ} \mathrm{I}^{\prime} \mathrm{S}$., long. $\mathrm{I}_{62^{\circ}} \mathrm{I}^{\prime} \mathrm{W}$., elevation $560 \mathrm{~m}$., ice thickness $775 \mathrm{~m}$., accumulation $\simeq \mathrm{I} 6 \mathrm{~g} . / \mathrm{cm} .^{2} \mathrm{yr}$., Io-m. temperature $-23^{\circ} \mathrm{C}$.) and on the Ross Ice Shelf near the border of Roosevelt Island (Fig. 3) (lat. $79^{\circ} \mathrm{oz}^{\prime}$ S., long. I $60^{\circ} 49^{\prime}$ W., elevation 6 o m., ice thickness $475 \mathrm{~m}$., accumulation $\simeq 30 \mathrm{~g} . / \mathrm{cm} .^{2} \mathrm{yr}$., I $\mathrm{o}-\mathrm{m}$. temperature $-26^{\circ} \mathrm{C}$.) can be explained by the 5 -layer models shown in Table I.

Table I. Layer Models for Resistivity

\begin{tabular}{cc}
\multicolumn{2}{c}{ Roosevelt Island } \\
Depth & \multicolumn{1}{c}{$\begin{array}{c}\text { Resistivity } \\
\mathrm{M} \Omega . \mathrm{m} .\end{array}$} \\
$\mathrm{m}$. & $\rho_{1}=0.65$ \\
$\mathrm{o}-\mathrm{I} 7$ & $\rho_{1}=0.22$ \\
$17-\mathrm{IOO}$ & $\rho_{2}=0.165$ \\
$100-400$ & $\rho_{3}=0.165$ \\
$400-75^{\circ}$ & $\rho_{4}=0.08$ \\
below $75^{\circ}$ & $\rho_{5}=0.50$ (rock)
\end{tabular}

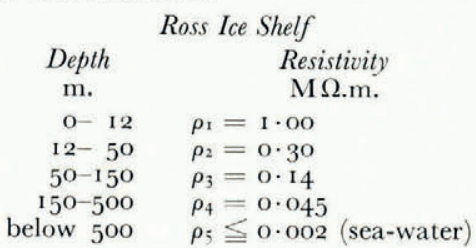

Lacking information about the effect of strain on the resistivity we will, in the following interpretation, treat the ice shelf in the same manner as an ice cap.

\footnotetext{
* The activation energy is not very sensitive to changes in the resistivity ratio; if for example we assume no further resistivity change due to pressure below about $70 \mathrm{~m}$. we obtain an activation energy of $\epsilon=0.5 \mathrm{eV}$.
} 
The two upper layers of these models approximate the steep decrease of resistivity to a depth of $100 \mathrm{~m}$. on the island and $50 \mathrm{~m}$. on the ice shelf. At these depths the rate of decrease apparently changes, causing a "plateau" in the apparent resistivity curve. The "plateaux" in the resistivity curves are very likely not due to inhomogeneities in the surface layers since all other resistivity curves on the island for example are nearly parallel to Figure 2 . The slow resistivity decrease between 100 and $75^{\circ} \mathrm{m}$. on the island and between $5^{\circ}$ and $500 \mathrm{~m}$. on the ice shelf can be approximated by two layers. The rate of decrease apparently changes at a depth of $400 \mathrm{~m}$. on the island and $150 \mathrm{~m}$. on the shelf ice, causing a second "plateau" in the resistivity curves. Below these depths, the apparent resistivity curves do not suggest further resistivity changes within the ice column. Furthermore, the calculated ice thickness of $75^{\circ} \mathrm{m}$. on the island and $500 \mathrm{~m}$. on the ice shelf agree quite well with seismic results. These facts suggest that the resistivity varies slowly within these layers, compared with rapid changes in the upper layers. The rock resistivity of about $0.5 \mathrm{M} \Omega . \mathrm{m}$. on Roosevelt Island is of the order of the resistivity of frozen rock measured at Devon Island (Apollonio and others, 196I).

Assuming that the resistivities of the multi-layered model are representative for the midpoint of each layer, i.e. coincidence of calculated and true resistivities at the mid-points, we should be able to estimate temperatures at these depths.

In Table II the depths of the central point of each layer are listed in the first column. The hydrostatic pressure at these depths (based on average densities from Antarctic pits and drill holes showing similar accumulation rates as Roosevelt Island) is given in the second column. The corresponding resistivities given by equation (3a) at surface temperature are shown in the third column. In the fourth column the calculated resistivities from the resistivity curves are listed. The difference between the two resistivities according to equation (I) gives the temperature difference $\Delta T$. A simple method determining $\Delta T$ consists of drawing a

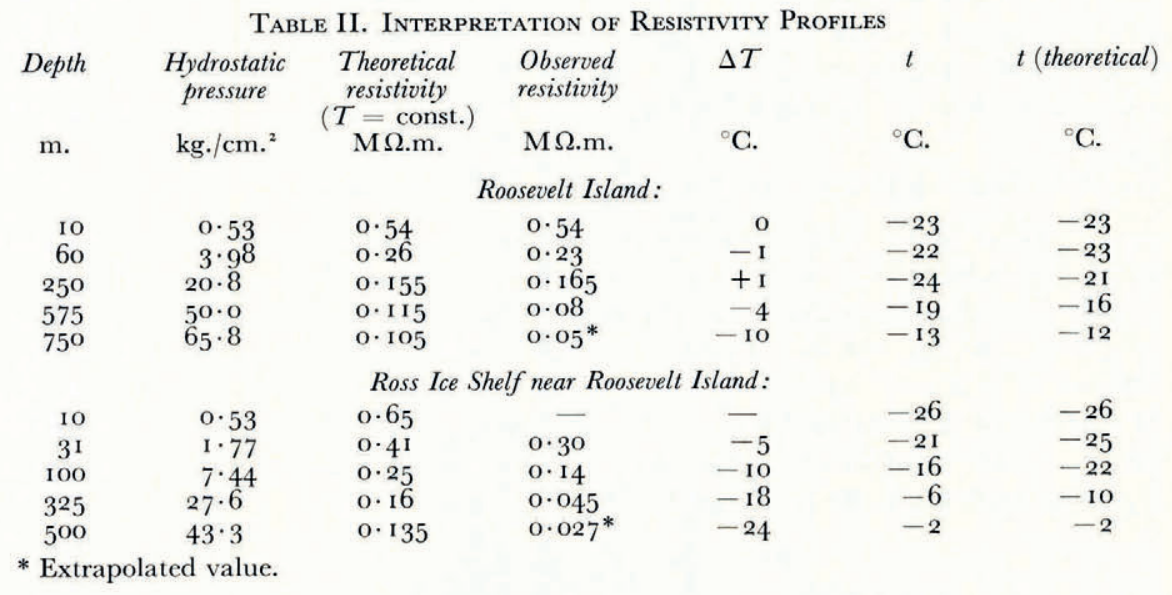

straight line with the slope $k / \epsilon$ on a plot of logarithm of resistivity against I/T through the point $\left(\rho_{1}, T_{1}\right)$. Theoretical temperatures for the centre of Roosevelt Island according to the theory of Robin (1955) and for the ice shelf near the island (no bottom melting) after Wexler (1960) are listed in the seventh column. At both locations these theoretical figures differ from the temperatures derived from electrical measurements. At Roosevelt Island, however, there is a fairly good agreement between the two temperatures if we allow a higher accumulation rate for the past (about $30 \mathrm{~g} . / \mathrm{cm}^{2} \mathrm{yr}$.; Fig. 5). On the ice shelf the temperatures from the electrical measurements agree poorly with theoretical values (Fig. 6). Higher accumulation rates or bottom melting would only enlarge the difference. The discrepancy may result from preferred crystal orientation brought about by high strain-rates. 


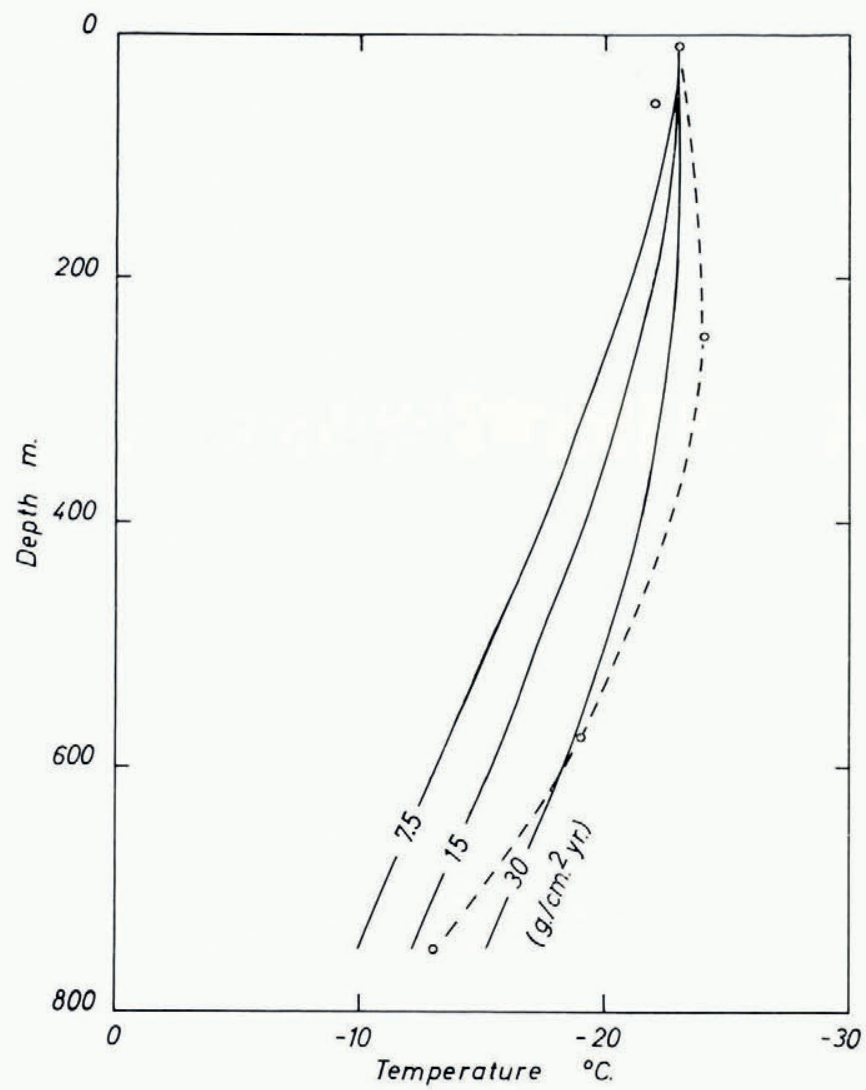

Fig. 5. Theoretical temperatures after Robin (solid curves with annual accumulation as parameter) and temperatures from electrical measurements (broken curve) for the ice cap of Roosevelt Island

The apparent resistivity curve at "Station Centrale", Greenland (Fig. I) (lat. $70^{\circ} 54 \cdot 6$ ' N., long. $40^{\circ} 38 \cdot \mathrm{o}^{\prime} \mathrm{W}$., elevation $2,965 \mathrm{~m}$., ice thickness 3 , I $90 \mathrm{~m}$., accumulation $\simeq 30 \mathrm{~g} . / \mathrm{cm} .^{2} \mathrm{yr}$., Io-m. temperature $-28^{\circ} \mathrm{C}$.) can be explained with the following four layer model:

$$
\begin{aligned}
& \text { Depth } \\
& \mathrm{m} \text {. } \\
& \mathrm{M} \Omega . \mathrm{m} \text {. } \\
& \text { O- } \mathrm{I} 2 \mathrm{O} \\
& \text { I } 20-280 \\
& \rho_{\mathrm{I}}=0.75 \\
& \text { 280-I } 200 \\
& \rho_{2}=0.1 \text { I } 5 \\
& \text { below } 1200 \\
& \rho_{3}=0.085 \\
& \rho_{4}=0.03
\end{aligned}
$$

The interpretation shows that down to $1,200 \mathrm{~m}$. depth the variation of resistivity can be explained by a decrease of the contact resistance according to equation ( $3 \mathrm{a}$ ) alone (except for the uppermost roo m.) which means that the temperature of the Greenland Ice Sheet at "Station Centrale" down to I,200 m. must be nearly constant. Nearly constant temperatures in the central region of ice sheets have been found in deep drill holes (Heuberger, I954; Wexler, I96I) but no measurements deeper than $35^{\circ} \mathrm{m}$. have been made. Approximately I. $2 \mathrm{~km}$. may be the depth at which the temperature on "Station Centrale" starts to increase relatively rapidly. This figure would agree with theories of temperature distribution in ice sheets (Robin, I955; Jenssen and Radok, I963) (Fig. 7). 


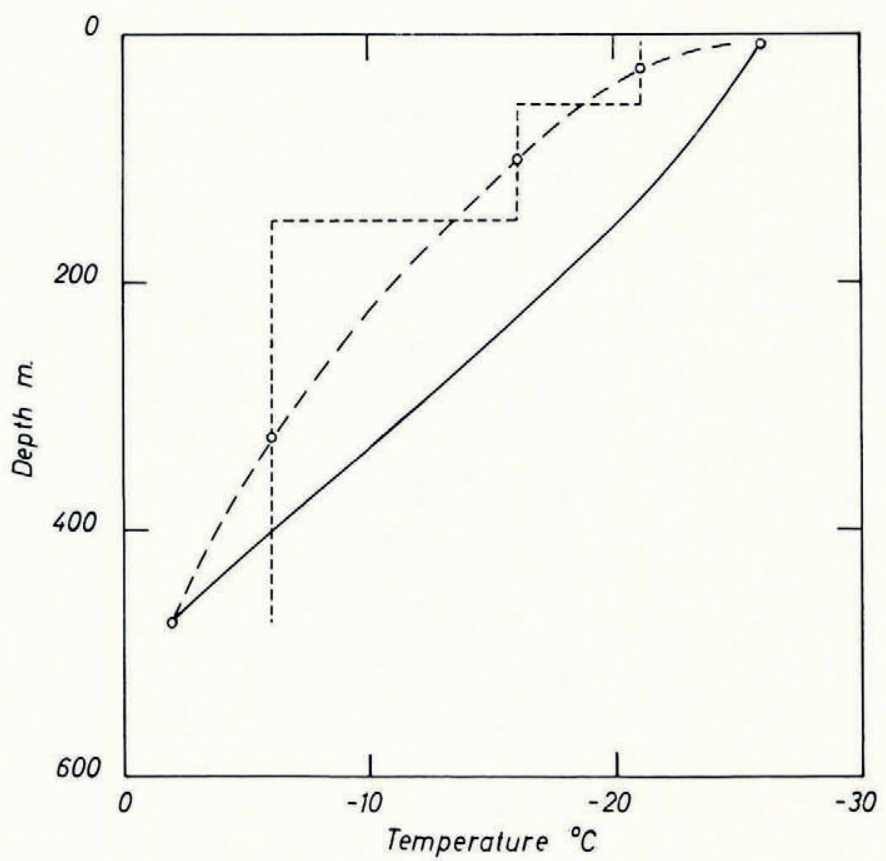

Fig. 6. Theoretical temperatures after Wexler (solid curve) and temperatures from electrical measurements (broken curve) for the Ross Shelf Ice near Roosevelt Island

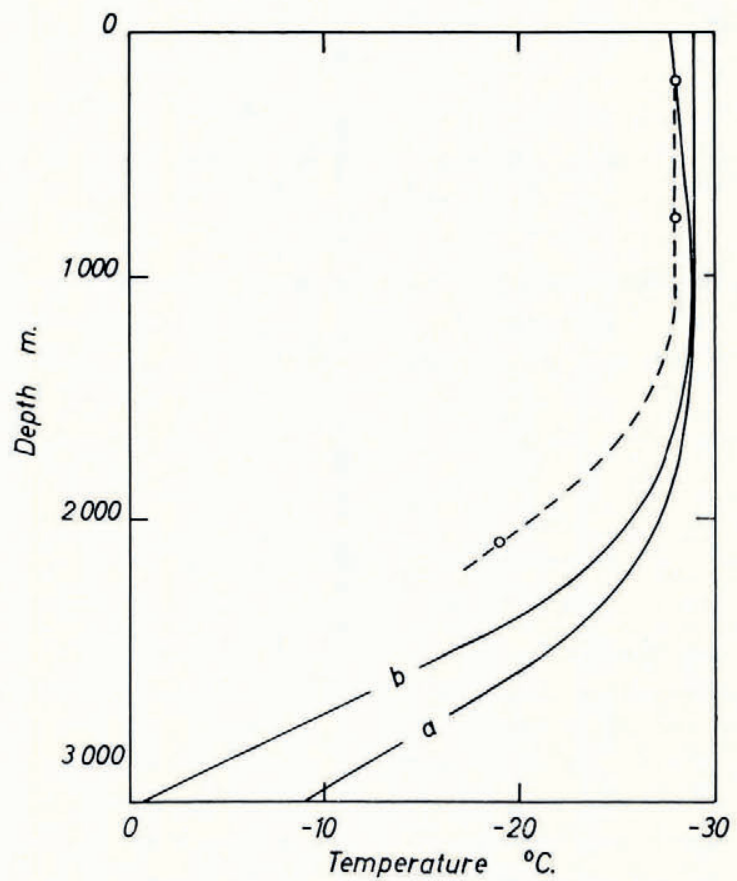

Fig. 7. Theoretical temperatures after Robin (solid curve $a$ ) and Jenssen and Radok (solid curve b) and temperatures from electrical measurements (broken curve) for "Station Centrale". Curve a was calculated assuming an accumulation of $30 \mathrm{~g} . / \mathrm{cm} .{ }^{2} \mathrm{yr}$.; curve $b$ allows for frictional heat at the bottom of the ice sheet due to an average movement of $30 \mathrm{~m}$. $/ \mathrm{yr}$. 
At the moment the relative error of the temperature differences derived from electrical measurements is quite large (about 35 per cent). This error contains the uncertainty about the true resistivity at a certain depth and the experimental error of the constants in equations ( $I$ ) and ( $3 \mathrm{a})$. More detailed measurements in the future and also handling multi-layered models according to Flathe's theorem with a computer will probably reduce the error.

\section{Summary}

Despite various reservations about the interpretation, this study shows that the resistivity on ice sheets is a function of the contact resistance between the grains and the temperature, if the effect of the structure of the snow and firn can be considered negligible. After eliminating the influence of hydrostatic pressure upon the contact resistance, we can explain resistivity variations by temperature variations which agree partly with theoretical temperatures.

A valuable contribution of the resistivity measurements on ice sheets seems to be the determination of the activation energy for the resistivity of cold sedimentary ice which was found to be much smaller $(\epsilon \simeq 0.4 \mathrm{eV} .=9.2 \mathrm{kcal}$./mole) than the value so far known from laboratory measurements.

\section{Acknowledgements}

The author wishes to acknowledge the assistance of Prof. B. Brockamp and the members of the geophysical group of the E.G.I.G., and the help of Dr. C. R. Bentley, J. F. Clark, R. Heidemann and W. Unger of the Roosevelt Island parties I $961-62$ and $1962-63$ during the field work.

MS. received ${ }_{14}$ September 1966

\section{REFERENCES}

Apollonio, S., and others. I961. The Devon Island expedition of the Arctic Institute of North America, by S. Apollonio, J. W. Cowie, K. Voegtli [sic], R. M. Koerner, P. Cress, R. Wyness and J. P. Greenhouse. Arctic, Vol. ${ }^{4} 4$, No. 4 , p. $252-65$.

Buchheim, W. 1958. Die elektrischen Aufschlussverfahren. (In Haalck, H. Lehrbuch der angewandten Geophysik. Berlin, Gebr. Borntraeger, p. 52-61.)

CGG (Compagnie Générale de Géophysique). 1955. Abaques de sondages électriques. Geophysical Prospecting, Vol. 3, Suppl. 3.

Flathe, H. 1955. A practical method of calculating geoelectrical model graphs for horizontally stratified media. Geophysical Prospecting, Vol. 3, p. 268-94.

Gränicher, H. 1958. Gitterfehlordnung und physikalische Eigenschaften hexagonaler und kubischer Eiskristalle.

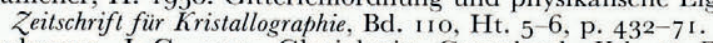

Heuberger, J.-C. I954. Glaciologie. Groenland. Vol. I: Forages sur l'Inlandsis. Paris, Hermann. (Actualités Scientifiques et Industrielles, I 2 I 4. Expéditions Polaires Françaises, [Travaux,] 5.)

Hochstein, M. 1965. Elektrische Widerstandsmessungen auf dem grönländischen Inlandeis. Meddelelser om Gronland, Bd. 17.7, Nr. 3 .

Jaccard, C. I959. Étude théorique et expérimentale des propriétés électriques de la glace. Helvetica Physica Acta, Vol. 32, Fasc. 2, p. 89-128.

Jenssen, D., and Radok, U. 1963 . Heat conduction in thinning ice sheets, fournal of Glaciology, Vol. 4, No. 34, p. $387-97$. Kopp, M. 1962. Conductivité électrique de la neige au courant continu. Zeitschrift für angewandte Mathematik und
Physik, Bd. ${ }^{13}$, Ht. 5, p. $43^{1-4}{ }^{1}$.

Meyer, A. U., and Röthlisberger, H. 1962. Electrical DC-resistivity measurements on glacier ice near Thule, Greenland. U.S. Cold Regions Research and Engineering Laboratory. Technical Report 87.

Robertson, E. I., and Macdonald, W. J. P. 1962. Electrical resistivity and ground temperature at Scott Base, Antarctica. New Zealand Journal of Geology and Geophysics, Vol. 5, No. 5, p. 797-8og. Robin, G. de Q. 1955. Ice movement and temperature distribution in glaciers and ice sheets. Fournal of Glaciology,
Vol. 2, No. 18, p. 523-32.

Wexler, H. r 960 . Heating and melting of floating ice shelves. Fournal of Glaciology, Vol. 3, No. 27, p. 626-45. Wexler, H. 1961. Growth and thermal structure of the deep ice in Byrd Land, Antarctica. Fournal of Glaciology,
Vol. 3, No. 30, p. $1075^{-87}$. 